\title{
Presentació
}

Teresa Torns (coordinadora)

Andreu Lope (director del Departament de Sociologia de la UAB)

Salvador C ardús, (professor de Sociologia de la UAB)

Louis Lemkow (vicerector de Relacions Internacionals)

\section{Teresa Torns}

EI D epartament de Sociologia de la U AB va impulsar la celebració d'unes jornades per parlar de qüestions relatives a l'avaluació de la recerca en les ciències socials. Les jornades varen tenir lloc el passat mes de febrer del $2001 \mathrm{i}$ varen poder comptar amb la presència del professorat dels departaments de Ciències Socials i H umanes de la U AB, que havien ajudat a dur a terme aquest projecte, a més de diversos vicerectors d'aquesta mateixa universitat i d'altres experts reconeguts en matèria avaluadora. La inauguració de les jornades va anar a càrrec del vicerector de Relacions Internacionals de la U AB L ouis Lemkow, professor del D epartament de Sociologia, i la cloenda va gaudir de la presència de l'al eshores degà de la Facultat de C iències Polítiques i Sociologia, Joaquim M olins, i amb la del conseller d'U niversitats, Recerca i Societat de la Informació, Andreu M as-Colell.

Els objectius de les jornades varen ser presentats per Salvador Cardús, en nom del D epartament de Sociologia. Les sessions es varen organitzar a manera de taules rodones. En la primera, hi van intervenir Joan Bellavista, del Parc Científic de la Universitat de Barcelona, i Salvador Barberà, professor del $D$ epartament d'Economia i $\mathrm{H}$ istòria Econòmica de la $U A B$, que hi assistia en qualitat de director executiu de la Institució $C$ atal ana de Recerca i Estudis Avançats (ICREA). Les seves intervencions varen tractar dels models de referència més habituals en l'avaluació de la recerca. A la segona taula rodona hi va intervenir la vicerectora d'Investigació de la U AB C arme Picallo, acompanyada pel també vicerector d'Investigació Jaume Bartrolí, que va parlar de les propostes i dels criteris avaluadors de la investigació utilitzats a la UAB. El segon dia hi va haver Joan Cals, professor del Departament d'Economia Aplicada de la UAB, M iquel Doménech, professor del D epartament de Piscologia de la Salut i Psicologia Social de la U AB i Joan Gómez, professor del D epartament de Ciències de l'Antiguitat i de l'Edat $M$ itjana. Tots varen intervenir en una taula rodona que pretenia formular propostes alternatives per a l'avaluació en ciències socials. A I'última taula rodona hi va haver dos convidats que varen parlar d'altres maneres de dur a terme propostes i criteris avaluadors en l'àmbit de la recerca. Eren Francisco Llera, professor de C iència Política de la Universitat del País Basc, i Alain d'Iribarne, director d'Investigació del CN RS. 
La celebració de les jornades acomplia una doble fita. D 'una banda, responia a la necessitat de satisfer el compromís signat pel D epartament de Sociologia en relació amb l'acompliment del contracte programa de la pròpia universitat. I, de l'altra, les jornades suposaven una esplèndida ocasió per debatre un tema sobre el qual els membres del $D$ epartament, conjuntament $a m b$ d'altres col-legues, havien mostrat, des de feia temps, un fort interès.

Les pàgines que segueixen recullen en bona mesura el que aquells dos dies de febrer es va dir sobre la qüestió de l'avaluació de la recerca en ciències socials. La majoria de l'escrit publicat respon a una transcripció literal del que es va dir, fruit de la gravació efectuada i sempre que aquesta transcripció ha estat possible reproduir-la. No ha estat així en tots els casos. En concret, no hem pogut reproduir les intervencions de Salvador Barberà ni de Jaume Bartrolí, ni el debat que va tenir lloc després de les taules rodones, un fet que lamentem molt de veres. A canvi, disposem de tres casos en els quals s'ha pogut tenir la reescriptura o l'escriptura d'un text original per ser publicat. En concret, es tracta dels textos de J oan Cals, de Joan Gómez i d'Alain d'I ribarne, els quals han tingut la possibilitat de refer per escrit el seu discurs oral. D es d'ací els volem agrair l'esforç i l'amabilitat. També reproduïm el que allí es va dir en els moments de la inauguració i de la cloenda, així com un document final que ha estat elaborat posteriorment, a manera de conclusions del que va ser dit i es va debatre durant les jornades. Un document que ha estat elaborat amb el consens d'un grup més reduit de participants que, en tot moment, no han volgut sinó recollir l'esperit de la tasca desenvolupada. Tot plegat, un conjunt de reflexions i arguments que, al nostre parer, presenten un alt interès i mereixen ser llegits $i$ debatuts perquè la recerca en ciències socials, i la recerca en general, respongui millor a les expectatives de totes aquelles persones que la duem a terme i volem sentir-nos i ser-ne plenament responsables.

Per últim, només resta agrair profundament l'assistència a tots els que varen ser presents a les jornades i van fer possible, amb les seves intervencions, l'alt nivell de reflexions i de debat assolit, així com la qualitat de la feina feta pels membres del D epartament de Sociologia, Àngela i Albert, sense els quals la materialització de les jornades no hagués estat possible. Gràcies i fins a la propera. 


\section{Andreu Lope}

Benvinguts $i$ benvingudes a aquestes jornades sobre avaluació de la recerca en ciències socials. I, de fet, amb aquestes paraules, jo ja podria acabar la meva intervenció, perquè, tal com veieu en el tríptic que suposo que tots teniu, a mi em pertoca donar la benvinguda als assistents, però, si em permeteu, diré alguna coseta més, no gaires.

D e fet, aquestes jornades són la continuació, una continuació ja prevista, ja volguda, d'unes altres que vam celebrar ara fa dos anys justos que pràcticament coincideixen fins $i$ tot amb les dates i que portaven com a títol «Primeres jornades sobre recerca». M algrat aquest títol, tampoc era la primera ocasió que els membres del $D$ epartament de Sociologia ens reuníem per debatre aquestes qüestions, però sí que és veritat que segurament en aquestes jornades de fa dos anys va ser el primer cop que dedicàvem tant temps $i$ tants esforços a tractar aspectes relatius a com fem recerca i quin tipus de recerca i per què la fem així en l'àmbit de la sociologia. Els objectius d'aquestes jornades que encetem ara, són ben diferents. No es tracta ja de posar en comú les experiències diverses del professorat del $D$ epartament en el terreny de la recerca, sinó que pretenem una al tra cosa.

Segurament, l'objectiu principal respon al propi títol que sha donat a les jornades. El que volem és debatre sobre avaluació de la recerca en ciències socials, i això depassa molt el propi terreny de la sociologia i del D epartament. Això vol dir que d'alguna manera que el que volem és discutir, debatre, quins són i com són els models i els criteris imperants i dominants pel que fa a l'avaluació de la recerca. Això vol dir també que el que volem és reflexionar sobre els problemes que aquests models imperants comporten per avaluar els tipus de recerca que es fa a ciències socials en general. I això vol dir en principi, també, que volem pensar i suggerir si és possible adoptar alternatives més o menys viables que permetin incorporar alguns elements propis de les ciències socials en aquests mecanismes d'avaluació.

De seguida, Salvador C ardús farà la presentació més acurada dels objectius i els continguts de les jornades, jo només volia dir un parell de cosetes més molt breus.

L'una és que fa uns quants mesos, precisament el D epartament de Sociologia va realitzar un contracte programa amb l'equip rectoral, que precisament en un dels seus punts molt concrets comportava el compromís per part del $D$ epartament de real itzar unes jornades sobre recerca en general. Un compromís que era absolutament i lliurement assumit per part del propi departament i que, a més, era una iniciativa que volíem dur a terme, volíem fer unes jornades com aquestes. Però és un compromís que comporta una certa parado$x a$, i és que es tracta d'un compromís que té a veure amb els mecanismes d'avaluació que poden derivar, jo no dic que derivin directament, però que poden derivar de la pròpia estructura, configuració i objectius del que és un contracte programa. El contracte programa no està destinat únicament ni prioritàriament a avaluar la recerca, però desenvolupa també un paper en aquest sentit. 
Vet aquí la paradoxa d'un compromís de realitzar unes jornades que tractin sobre l'avaluació de la recerca i que està adquirit en un element del contracte programa que també té un paper en aquest sentit.

H e dit només dues cosetes, aquesta era la primera, molt ràpidament comento la segona i última qüestió. Aquesta última qüestió és que jo crec que val la pena deixar constància dels deutes, entre cometes, que el D epartament ha adquirit amb determinades persones que, amb els seus esforços i la seva dedicació, han fet possible la concreció d'aquestes jornades. Q uan dic «deutes», em refereixo a un concepte que espero que es prengui en un sentit absolutament figurat, evidentment, perquè l'únic tipus de remuneració és el que ara faré, que és la d'una sèrie d'agraïments a aquestes persones. Agraïments que no són en absolut protocol'laris, això sí que és ben veritat, sinó ben sentits. Aleshores, evidentment, jo diria que la coordinació i l'organització i la celebració efectiva de les jornades es deuen fonamentalment als esforços que hi ha dedicat la coordinadora de recerca del D epartament, la professora Teresa Torns, en aquest sentit, val a dir que és la màxima responsable, entre cometes, que avui i demà ens trobem per discutir i parlar sobre aquests temes. En segon Iloc, val la pena dir que és veritat que aquestes jornades s'organitzen des del $D$ epartament de Sociologia, però en el propi tríptic s'indica que hem tingut la col-laboració de professorat d'altres àrees de ciències socials. Aquesta col-laboració, que ha estat efectiva i molt determinant, I'han realitzat persones molt diverses, alguna de les quals serà també en alguna de les taules rodones que realitzarem al Ilarg d'aquests dies, d'altres no, però, en qual sevol cas, la col-laboració d'aquestes persones, insisteixo, ha estat determinant per delimitar, configurar una mica el perfil de les pròpies jornades, i val la pena esmentar-ho.

Crec que cal deixar constància també del nostre agraïment a l'equip de govern de la U niversitat Autònoma de Barcelona per diverses raons, però per una de fonamental: en les dues sessions d'avui i de demà hi haurà la presència, que estava prevista, de, ni més ni menys, quatre vicerectors. Avui n'hi ha un cinquè que no estava previst en aquesta sessió, em refereixo concretament a Louis Lemkow, que comparteix la sessió d'obertura. A dos quarts d'una tindrem amb nosaltres Carme Picallo i Jordi Bartrolí, vicerectors de Recerca. En la sessió de cloenda, malgrat que no figura en el tríptic, perquè la seva participació es va concretar en els últims dies, tindrem entre nosaltres L luís Ferrer i avui tenim també Ferran Sancho, que ha pogut fer un forat per assistir a aquesta sessió. Val la pena fer esment d'aquesta qüestió també.

Ò bviament, cal afegir-hi un agraïment molt particular a les persones de fora de la $U A B$ que ens dediquen el seu temps en alguna de les taules rodones que real itzarem i que han estat escollides, per dir-ho d'alguna manera, pel que fa a les seves tasques vinculades a recerca. M oltes d'aquestes tasques, a més a més, han estat aplicades al terreny de l'avaluació de la recerca i poden oferir-nos elements significatius per al debat.

Finalment, en el capítol d'agraïments voldria deixar constància molt personalment que cal agrair també les tasques que han desenvolupat I'Ȧngela Palau 
i l'Albert des de la secretaria del $D$ epartament i que han fet possible la materialització real, concreta, de veritat, d'aquestes sessions.

Bé, no tinc res més a dir. Salvador $C$ ardús ens comentarà més acuradament els objectius i el funcionament de les jornades i en Louis Lemkow, en la seva doble qualitat de vicerector de Relacions I nternacionals i de professor del D epartament, en realitzarà l'obertura oficial. 


\section{Salvador C ardús}

D e manera també breu, perquè això és només una declaració, diguem-ne, de principis, no és entrar pròpiament en el debat, penso que és convenient mirar de centrar tant com sigui possible els objectius d'aquestes jornades: quèés el que ens preocupa i de què ens agradaria parlar. Llavors veurem si som disciplinats i si no acabem parlant com sempre dels orígens del món, però de moment les jornades sí que tenen un objectiu o que tenien un objectiu específic que m'agradaria concretar.

El D epartament de Sociologia, com m'imagino que passa a la major part de departaments d'aquesta universitat i d'altres, està clar i no és discutible que té interès per millorar i incrementar els seus projectes de recerca. Per millorar en termes de qualitat i per incrementar el que és la seva activitat investigadora. No és una qüestió que s'hagi de discutir, és una qüestió com a punt de partida que forma part del sou que cobrem i és la nostra obligació, per tant, aquesta qüestió no entra en debat. Tampoc no entra en debat, per part d'aquest departament ni en el plantejament de les jornades, la discussió sobre la necessitat d'avaluar aquesta recerca. Ens sembla claríssim la necessitat de fer-ho. Sempre recordo una intervenció del doctor Barberà en una celebració, em sembla que era els deu anys de memòries de recerca d'aquesta universitat. Va començar fent una observació que em va quedar viva en la memòria perquè és d'aquelles observacions prèvies i intel.ligents necessàries. Ell va dir: «D 'acord, avaluem, sempre que sapiguem per què ho fem». 0 sigui, si és avaluar per molestar, no cal, perquè moltes vegades sí que tens la impressió que s'avalua perquè toca fer-ho, pero no saps exactament quins seran els resultats o els objectius. Per tant, estem d'acord que s'ha d'avaluar, però, naturalment, sempre que sapiguem per què avaluem i sempre que sapiguem què en fem d'aquesta avaluació, entre d'altres coses perquè depèn del que n'haguem de fer hauríem d'avaluar d'una manera o d'una altra, hauríem d'avaluar unes coses o n'hauríem d'avaluar unes altres, per tant, fins aquí cap problema. Pensem que hem de millorar els nostres projectes de recerca i pensem que s'han d'avaluar. Pensem que aquesta avaluació ha de tenir conseqüències, o sigui que no és una pura qüestió de fer un quadre d'honor, sinó que ha de tenir repercussió sobre la nostra pròpia activitat, i aquesta avaluació ha de contemplar tant la qualitat com l'extensió o la intensitat, això ho dic per no fer servir la paraula lletja, que és la productivitat. També probablement podem trobar eufemismes, però sempre hem de mesurar la nostra productivitat, perquè és una responsabilitat social que tenim.

Ara bé. $D$ it això, s'ha de fer, i aquí vénen els problemes, fins aquí tots d'acord, però sorgeixen algunes qüestions de les quals cal parlar. En primer Iloc, i com a nota prèvia, la veritat és que la cultura de l'avaluació és una cultura en la qual tot just hi estem entrant, i inicialment genera moltes suspicàcies, moltes desconfiances. Jo crec que de vegades perquè en el mateix plantejament dels qui proposen l'avaluació, per no ofendre, per no semblar que entren al galop, es fan tantes precaucions inicials que més aviat es tanquen, és a dir, quan 
la gent comença a dir: «N o patiu, no passa res, no tindrà cap efecte sobre cap qüestió sobre pressupostos». Q uan et comencen així, ja tremoles, perquè penses que finalment acabarà tenint al gun efecte, és a dir, que tantes excuses inicials més aviat creen desconfiança. Perquè en general sí que hi ha un cert clima de desconfiança, no diré universal, però relativament estès. M oltes vegades, a causa de resistències merament culturals, diguem que no ens agrada que mirin el que fem, com ens va costar signar els fulls de control de classe, com ens costa acceptar els resultats de les enquestes que han respost els alumnes... Tot això inicialment crea resistències.

$\mathrm{Hi}$ ha aspectes que ajuden a patir aquestes desconfiances, i no només són problemes, diguem-ne, culturals. També moltes vegades els resultats d'avaluacions que s'han fet no han quedat clars, perquè havien servit exactament en el sentit que deia abans de Barberà. M oltes vegades has tingut la impressió d'entrar en uns processos d'avaluació molt estandarditzats, molt burocratitzats, però amb molt poca capacitat de tenir conseqüències sobre res. Jo he participat en el procés d'avaluació de les biblioteques de manera molt directa, ara estem en el procés d'avaluació de la titulació de sociologia. Dirigeixo el comitè d'avaluació i per tant sé de què parlo i sé fins a quin punt costa estirar, costa implicar tothom en aquesta mena de processos i, a més a més sense saber exactament què els pots prometre que passarà al final de tot això. Perquè de vegades hi ha elements objectius que indueixen a la desconfiança, quan, per exemple, se t'acut demanar, com ens va passar a nosaltres. $\mathrm{H}$ i ha un sistema a instàncies i a suggeriment del professor Estruch de dir: «Escolta'm, a la universitat ja n'hi ha un de sistema de mesura de la qualitat de la recerca, que són els trams\%. N osaltres ja passem unes proves $i$ ens mesuren quins trams de recerca hem passat. I demanes aquesta informació i resulta que no és pública. Resulta que, per una banda, hem d'avaluar la recerca, però els únics criteris objectius i externs que fins ara hi ha hagut i el màxim que hem tingut i que es veu que és I'únic que es pot tenir és el total de tanta gent que som, tots plegats sumem tants trams de recerca. Però, és clar, dit així és una mesura molt imprecisa. I, a més a més, no sabem quants trams cadascú, si està concentrat en un dos o en un tres 0 si tots en tenen un. Per tant, és una mica contradictori en tots aquests processos en el punt on som. Ara bé, aquesta és una nota prèvia, no reflecteix necessàriament totes les dificultats que trobem, sinó que a mi em sembla que bàsicament n'hi ha tres, de dificultats, que sí que m'agradaria precisar.

Una. Si més no en aquest departament, perquè és un departament que no crec que sigui gaire diferent d'altres de la universitat, però sí que és veritat que és especialment heterogeni des de la seva fundació i al llarg de tota la seva història, per tant, hi ha gent que hi treballa des de tradicions tant teòriques com metodològiques molt diverses. Aquesta heterogeneïtat que fa que hi hagi des de grans grups, o des d'un gran grup de recerca, tampoc tant grans, però un que en fa molta, que aglutina molt professorat que realitza un treball podríem dirne «d'erudició i artesà» i de molta qualitat, però que és un treball individual, i Ilavors naturalment totes les vinculacions amb I'ICE o les vinculacions amb I'Institut d'Estudis M etropolitans, o vinculacions amb institucions externes 
que tampoc moltes vegades no saps com incorporar a aquests treballs que es realitzen dins del que es fa al mateix departament, perquè ja costa, fins i tot burocràticament, saber incorporar la val oració d'aquesta recerca. Tota aquesta heterogeneitat fa que es plantegin alguns problemes, que són els que, de manera molt accentuada, vull esmentar.

En primer Iloc, no tota la nostra recerca es fa amb finançament públic. I fins i tot una part important de la nostra recerca es fa sense cap finançament, que D éu n’hi do. No és que vulgui ser injust, però sí deixeu-me assenyalar amb el dit, malgrat que sigui de mala educació. El professor Estruch pot fer una recerca sobre l'O pus, publicar-la primer als Estats U nits, publicar-la en català, en castellà, en alemany..., una recerca que té un interès a tot arreu, una recerca d'alta qualitat, però ho fa a les seves hores de treball que li queden lliures després de la seva jornada docent. N o té finançament públic per fer aquesta recerca, la qual ha estat realitzada al Ilarg d'uns quants anys de dedicació. Aquesta recerca, segons els paràmetres d'avaluació de la nostra recerca, no compta. N o forma part de les mesures habituals, o de les mesures més habituals de comptabilitzar l'excel lència d'aquest departament. No dic que no hi hagi mesures indirectes que ho puguin incorporar com a publicació, però això no és el resultat d'un projecte finançat amb deu milions de pessetes ni per la UE, ni pel govern de $M$ adrid.

Per tant, no tot es finança a través de projectes públics ni de convenis i, per tant, molt bona part de la recerca queda fora d'aquest marc avaluable. En segon Iloc, no tot el treball de recerca l'anomenem estrictament «treball de recerca». Aquí, això ens planteja un al tre tipus de problemes, el problema que shi planteja és saber si la universitat entén estrictament que és la recerca científica o estrictament científica.

Jo crec que nosaltres, en aquestes jornades, no venim a discutir què és ciència i què es considera ciència, sinó que volem dir: «D 'acord, només serà ciència el que convingui que sigui ciència, però hi ha tota una al tra sèrie d'activitats que són paral·leles, immediates al que és l'activitat científica, i voldríem saber si això s'ha d'avaluar o no, si compta com a feina o no compta com a feina». És a dir, un tipus de treball, uns dictàmens per a organismes públics perquè demanen, per exemple, avaluació d'altres projectes de recerca o perquè el Consell Audiovisual de Catalunya demana un dictamen sobre uns estudis que s'han fet sobre el tractament de la immigració en els mitjans de comunicació catalans. Fer un dictamen d'aquest tipus, és investigació?, no és investigació?, forma part de la universitat?, se'n beneficia o no se'n beneficia? ho vol tenir en compte?, si fas això perds el temps?, quedes fora de joc?, no et comptarà per a l'avaluació?, aquesta és la qüestió. No només dictàmens, sinó també assessoraments a d'al tres tipus de disciplines... Per exemple, jo conec químics que es dediquen a treballar, per a les companyies vinícoles i els mesuren la qualitat del vi, no? I per tant són feines al servei d'assessoraments tècnics per a determinades empreses. Si nosaltres fem això, moltes vegades no va acompanyat d'uns contractes especialment elevats, perquè el mercat en què en movem és d'un altre tipus. El fet que realitzem aquest tipus de feines forma part de la 
nostra tasca, però, es pot avaluar això?, no es pot avaluar? o és com si no féssim res? Q uan llavors hem de demanar de presentar-nos a una càtedra d'aquestes extraordinàries..., el currículum et queda ple o et queda buit? Una d'extraordinària 0 una de normal?

I no cal dir que hi ha encara tot un altre camp del qual no en voldria parlar gaire perquè no semblés que parlo d'una part de la feina que, per exemple, faig jo, però que sí que com a mínim l'he d'esmentar, que és tota la tasca més pròpiament de divulgació. Perquè no tot és treball de creació, no tot és treball d'innovació científica, sinó que hi ha una part molt important de la nostra feina que pot dedicar-se, podria dedicar-se (en d'altres països sembla que fins i tot ho preveuen i ho avaluen) a contemplar la necessitat, l'obligació de fer la divulgació, a àmbits més generals de la població, dels resultats d'aquesta recerca. H em de saber si la divulgació també compta per a alguna cosa o no compta per a res. El que és la publicació de llibres, que jo no diré mai que siguin ni científics i ni de sociologia, però probablement són de divulgació de les nostres reflexions, dels nostres treballs, són intervencions públiques..., el que sigui. Això, té algun interès per a la universitat o no té cap interès per a la universitat?

H i ha una tercera qüestió que també em sembla que plantejàvem quan discutíem l'organització d'aquestes jornades, que és la qüestió del fet dels criteris estàndards d'avaluació de la recerca perquè són uns criteris que sovint perjudiquen el tipus d'objectes que es tracten des de les ciències socials, però no només en aquest àmbit, perquè hem parlat amb gent que es dedica, per exemple, a la botànica i que es troba exactament amb la mateixa dificultat, perquè si treballa durant vuit anys fent un mapa de la flora i la fauna de Sant Llorenç del M unt, les possibilitats de publicar aquests resultats en una revista nordamericana són escassíssimes. M 'explicaven I'al tre dia que sempre troben al guna via de publicar a l'estranger a través de revistes, per exemple..., russes. Es veu que als països de l'Est hi ha moltes revistes, que ara deuen estar mancades de treballs. I, per exemple, hi pots publicar «La flora i la fauna de Sant Llorenç del $M$ unt» en anglès en una revista editada a M oscou i esperar que això permeti entrar en els circuits internacionals, però no és segur que hi puguis acabar entrant i això no vol dir pas que aquest treball no tingui una qualitat i un rigor extraordinaris, però no entra dins dels circuits avaluables.

És clar, no tots ens dediquem a estudiar la sida, no tots ens dediquem a estudiar els problemes del cor, no tots ens dediquem al problema del trasplantament de ronyons. Si us fixeu en quins són els científics catalans que se citen més a l'àmbit internacional, sempre són en aquests tipus de continguts, que efectivament tenen un interès universal. Si tu et dediques a la cardiologia, com que fins ara, i ara encara més, ja sabem que els cors són exactament tots iguals, tens l'avantatge que un cor d'un català o fins i tot el cor d'un porc català diem que sobre el que investiguen és pràcticament idèntic al dels porcs d'arreu del món, i això és un gran avantatge. Però els nostres objectes no són com els porcs, no són universals, sinó que nosaltres tenim uns objectes d'àmbit limitat, i que llavors sovint el teu tipus de treball, el teu objecte d'interès, pot tenir 
fins i tot una gran transcendència social, però, naturalment, a una revista nordamericana no li interessa per a res la teva reflexió sobre el context en el qual I'has estat desenvolupant. Si l'avaluació del resultat dels nostres treballs s'ha de fer en base a rànquings de revistes bàsicament d'àmbit anglosaxó, per no dir directament nord-americà, si resulta, com ens va passar veient el rànquing, per exemple de les revistes, una revista de dret de la Universitat de Texas tenia unes cinc vegades més de puntuació que les Actes de la Recherche de Bourdieu, simplement perquè Bourdieu publica en francès i per tant la seva revista està francament mal valorada dins del què són el s rànquings de les revistes quan nosaltres la considerem important, això vol dir que aquí passa al guna cosa. És a dir, que el problema no és estrictament de qualitat, sinó de dominis, d'hegemonies lingüístiques, d'hegemonies polítiques..., d'altres problemes que, en fi, tampoc no hem de pagar-ne pas el preu directament, per tant necessitem altres instruments, ja que és un problema d'universalitat dels objectes, és un problema d'hegemonies polítiques i d'hegemonies lingüístiques, etc.

Per tant, jo crec que, bàsicament, el problema està conformat per aquests tres aspectes, que són: no tota la recerca passa per finançament públic, no tot el treball de recerca és científic, ja ho admetem, però hi ha altres tipus de treball que ens sembla que són universitàriament respectables i valuosos i, finalment, els criteris d'avaluació que existeixen, que en aquests moments tenim damunt la taula no fan justícia a les investigacions científicament valuoses que tenim en el nostre àmbit de treball, perquè sovint queden fora d'aquests marcs. Per exemple, nosaltres moltes vegades solem publicar llibres en lloc d'articles i resulta que en molt bona part, l'esforç que representa escriure un Ilibre queda fora dels sistemes d'aval uació privilegiats.

En conclusió, no m'allargo més. Com he dit al començament: ni discutim que convingui avaluar, ni discutim que convingui treballar millor i produir més. Em sembla que això no hi ha ningú que ho discuteixi. No discutim tampoc que els criteris de cientificitat puguin excloure una part molt important de la nostra feina com a investigadors. Aquests criteris es basen en opinions estrictes, rigoroses i respectables de cientificitat que consideren que la nostra tasca és de segon ordre, que no és al ta ciència..., perquè si ho discutíssim potser tampoc no ens posaríem d'acord. El que ens demanem és, precisament, quin hauria de ser aquest àmbit de la recerca en un sentit ampli, què és el que la universitat vol considerar com a treball universitari a part del que és estrictament la docència. Si admet que hi ha altres aspectes que no siguin estrictament els projectes més de rigor científic. Si considera que això és socialment valuós, si això la justifica socialment, si la justifica públicament, si justifica les inversions que fa. N aturalment, la meva impressió és que sí, pero valdria la pena que ho diguéssim i, si és així, com incorporem tot aquest treball a l'hora d'avaluar el rendiment del nostre professorat, de les persones que treballem aquí?, per tant, quin és aquest àmbit, l'àmbit reconegut? Q uins són els criteris de qualitat, interns i externs? Externs sí, però que no siguin d'aquests que són forasters, és a dir, que no s'adonen del que fem. Externs vol dir que sabent de què parlen, ens avaluen des de fora criteris de qualitat interns i externs, i en 
definitiva també, de manera més concreta quines formes de control o de registre alternatius als actuals podríem imaginar. Perquè si alguna cosa ens preocupa i finalment és el que va justificar que ens decidíssim a proposar aquestes jornades, que la Teresa Torns les impulsés, és el fer de dir: «Sabem que no ens agrada el que tenim que ens sembla que no és adequat, però el que també sabem és que no és responsable només fer la crítica dels models que no ens agraden sense ser capaços de proposar algun model alternatiu que sigui acceptable per a tota la comunitat». I, per tant, el que a nosaltres ens agradaria és que després d'aquestes jornades fóssim capaços de tenir alguns criteris, alguns criteris millors per saber efectivament com controlar, com registrar, com avaluar aquest treball que ens sembla a nosaltres modestament que també és valuós i que la universitat hauria de poder-se'n servir i hauria d'incorporar-ho, també en bé no només nostre sinó de la universitat ho hauria de poder incorporar com un treball que es genera aquí, que es fa des d'aquí i, per tant, que contribueix a la millora de la mateixa universitat. Aquestes em sembla que eren les idees clau d'aquestes jornades i les que ens agradaria poder discutir al llarg del parell de dies que duren. 


\section{Louis Lemkow}

Em toca fer el paper formal i institucional, i això em produeix una certa incomoditat, perquè ens coneixem tots, i aquest és el meu departament, la meva facultat, però, bé, volia afegir alguns comentaris, dir algunes «cosetes»..., moltes coses s'han dit ja, i jo crec justament que és la fórmula base de la intervenció de Salvador $C$ ardús el debat que ens toca fer, i estic molt d'acord en això, però has utilitzat la paraula lletja, antipàtica, productivitat, que ens provoca molta inquietud, moltes vegades, i no és veritat. Es provoca un cert rebuig i una certa inquietud a la universitat quan es parla en termes de productivitat, i ho entenc, però jo crec que no hem de fugir de parlar del que fem a la universitat en l'àmbit de la recerca. Som una institució pública i tenim justament aquesta responsabilitat de ser transparents i d'explicar a la societat el que fem, però no solament hem de rendir comptes a la societat, explicar-li quèfem, sinó que també és important des del punt de vista intern. Cal comptar amb aquesta transparència, saber el que es fa als diferents departaments, jo penso que és un element important i és una mena d'obligació fer-ho, però és cert que efectivament durant els últims deu, quinze anys ha crescut molt la productivitat en ciències socials, malgrat que mesurar això és complicat... I justament, paral. lelament amb el creixement, s'han anat articulant formes d'avaluar. EI que es fa aquí a l'Autònoma a l'àmbit de la recerca i justament articular els models d'avaluació ha aixecat crítiques i un debat important, i és normal i ha de ser així, perquè efectivament l'avaluació de la recerca és molt difícil i jo crec que s'ha dit molt clarament. Primerament, tenim una dificultat entorn del que es pot comptabilitzar com a recerca... És difícil, tenim dubtes, i això comporta una dificultat d'entrada, és a dir, la recerca, les activitats que fem a través de convenis amb empreses 0 amb institucions, algunes persones han dit 0 al-leguen que això no és recerca, d'altres que efectivament ho és..., ja d'entrada tenim una dificultat notable, tot i que és normal que hi hagi un qüestionament d'aquest procés d'articulació d'un sistema d'avaluació i seguiment de la recerca.

També una cosa que s'ha imposat des dels governs, els trams, també ha provocat moltes inquietuds. Lligar, diguem, els ingressos dels professors amb una avaluació de la recerca i basar-ho en el sistema de trams és el que hi ha, però jo entenc també que això ha aixecat recels i dificultats.

Jo no hi volia afegir res més, simplement volia dir que entenem les dificultats. Jo crec que la voluntat del rectorat des de l'equip de govern és justament la de mantenir un debat, que s'estableixi una interacció entre tots nosaltres i també aconseguir aquesta transparència que he comentat abans. També hi ha, sha de reconèixer, l'esforç i l'interès del D epartament de Sociologia, perquè no són les primeres jornades que organitza, se n'han celebrat d'altres i aquest compromís també està formalitzat a través del contracte programa, perquè hi havia un compromís de fer aquestes jornades. Bé, amb això no voldria dir res més, solament vull declarar oficialment inaugurades aquestes jornades. Gràcies. 